\title{
Intravascular Profile of Coronary Artery Disease in Diabetic Patients with Acute Coronary Syndrome: Results of the Saudi Coronary Athero-Thrombotic Disease (SAUDICAT)
}

\author{
Samih Lawand1, Sarah Albabtain1, Khalil Houissa', Anas Kodeih1, Musaab Aljuaid1, \\ Abdelfattah Alsfar ${ }^{1}$, Ahmad Bahnassy' ${ }^{1}$, Stéphane Carlier ${ }^{2}$ \\ ${ }^{1}$ Adult Cardiology Department, Prince Salman Heart Center, King Fahad Medical City, Riyadh, Saudi Arabia \\ ${ }^{2}$ Department of Cardiology, Faculty of Medicine and Pharmacy, UMONS, Mons, Belgium \\ Email: Stephane.Carlier@umons.ac.be
}

How to cite this paper: Lawand, S., Albabtain, S., Houissa, K., Kodeih, A., Aljuaid, M., Alsfar, A., Bahnassy, A. and Carlier, S. (2017) Intravascular Profile of Coronary Artery Disease in Diabetic Patients with Acute Coronary Syndrome: Results of the Saudi Coronary Athero-Thrombotic Disease (SAUDICAT). World Journal of Cardiovascular Diseases, 7, 174-184. https://doi.org/10.4236/wjcd.2017.75016

Received: December 31, 2016

Accepted: May 24, 2017

Published: May 27, 2017

Copyright ( 92017 by authors and Scientific Research Publishing Inc. This work is licensed under the Creative Commons Attribution International License (CC BY 4.0).

http://creativecommons.org/licenses/by/4.0/

\section{c) (i) Open Access}

\begin{abstract}
Cardiovascular disease is the leading cause of mortality in patients with diabetes mellitus (DM). We sought to establish for the first time in Saudi Arabia an intravascular ultrasound (IVUS) profile of DM patients with acute coronary syndrome (ACS). Patients and methods: We retrospectively analyzed 210 IVUS studies in 181 patients hospitalized in King Salman Heart Centre for ACS. IVUS was performed to guide percutaneous coronary interventions (PCI) of borderline moderate lesions. Results: Mean age was $58 \pm 10$ years, $78 \%(\mathrm{n}=163)$ of IVUS studies were performed in men. There were $71 \%(\mathrm{n}=$ 128) patients with DM. ST elevation myocardial infarction (STEMI) was the most common clinical presentation ( $47 \%, \mathrm{n}=88$ patients). As compared to non-DM, the intermediate lesions of DM patients had a significantly larger IVUS plaque volume $\left(267 \pm 174 \mathrm{~mm}^{3}\right.$ versus $\left.193 \pm 111 \mathrm{~mm}^{3}, \mathrm{p}<0.01\right)$, vessel volume (496 $\pm 314 \mathrm{~mm}^{3}$ versus $\left.358 \pm 182 \mathrm{~mm}^{3}, \mathrm{p}<0.01\right)$, lumen volume (231 \pm $156 \mathrm{~mm}^{3}$ versus $\left.164 \pm 88 \mathrm{~mm}^{3}, \mathrm{p}<0.01\right)$ and longer lesions $(37 \pm 12 \mathrm{~mm}$ versus $30 \pm 8 \mathrm{~mm}, \mathrm{p}<0.01)$. A positive remodelling index was observed for $\mathrm{pa}$ tients with and without DM, without significant difference (1.4 versus 1.3 respectively, $\mathrm{p}=0.7$ ). Percent plaque volume and obstruction were not different. Conclusion: IVUS demonstrates longer lesions to be treated in DM patients with ACS in Saudi Arabia, however no difference in average plaque burden or remodelling index. These findings are likely to impact our understanding of optimal PCI strategies in DM patients.
\end{abstract}




\section{Keywords}

Intravascular Ultrasound, Diabetes Mellitus, Acute Coronary Syndrome

\section{Introduction}

Coronary artery disease $(\mathrm{CAD})$ remains the main cause of death in patients with diabetes mellitus (DM) [1]. Diabetes affects nearly one in ten adults and its prevalence is increasing worldwide [2]. The epidemic situation is even worse in Middle East countries, especially in Saudi Arabia where DM prevalence in adults reaches $23.7 \%$ [3] and CAD affects $5.5 \%$ of the population [4].

The coronary artery lesions in diabetic patients are more extensive and diffuse. Revascularization therapies are still debated and clinical outcomes after either percutaneous coronary interventions (PCI) or coronary artery bypass graft (CABG) are poorer than in non-diabetic patients [5].

The cardiac catheterization laboratory at King Salman Heart Centre is the leading center in the use of intravascular ultrasound (IVUS) in Saudi Arabia and the region: $\sim 30 \%$ of PCI are IVUS-guided (unpublished data). We embarked on investigating the spectrum of Coronary Athero-Thrombotic Disease of Saudi patients (SAUDICAT) presenting with Acute Coronary Syndromes (ACS). Our aim was to establish a database of anatomically defined Athero-thrombotic disease in Saudi nationals in Diabetic compared with Non-Diabetic (NDM) patients. While coronary angiography offers only the possibility to scan the luminograms, IVUS also provides detailed information about the extent of the disease and the conformational changes within the vessel walls over the length of the lesion. Ultrasonic examination typically reveals three-layered components of the coronary wall: the intima, the media and the adventitia, each of which possess a variable echogenicity.

Since the clinical course and outcomes of DM patients are in many ways more challenging and pose considerable stresses on optimal management including the choice of the most appropriate interventions, we opted to study our largely diabetic population of Saudi patients who presented with ACS.

The selection of intermediate lesions for IVUS evaluation was considered more appropriate in order to avoid plaque distortion by prior ballooning of more severe lesions. IVUS provides real-time high resolution cross-sectional tomographic images from lumen and vessel wall. Current intracoronary ultrasound catheters typically range in size from 2.9 to 3.5 French $(0.96-1.17 \mathrm{~mm}$ in diameter) and can therefore only be used in the proximal and mid segments of the coronary arteries and in the absence of tight coronary stenosis. IVUS is commonly used in high volume PCI centers, but its use is limited to certain interested and trained operators.

\section{Material and Methods}

This is a retrospective study conducted at King Fahad medical city. All proce- 
dures performed involving human participants were in accordance with the ethical standards of the national research committee. An informed consent was obtained from all individual participants included in this study. A total of 504 IVUS studies in 441 patients were reviewed. The indication for the IVUS studies was to evaluate angiographically intermediate coronary lesions. All IVUS studies were screened in order to exclude from the current analysis IVUS runs performed in patients with instent restenosis, runs that were technically inadequate or without automatic pullback. Of all the reviewed IVUS runs a total of 210 IVUS studies in 181 patients were considered suitable for analysis in keeping with the inclusion/exclusion criteria summarized in Table 1.

\subsection{Clinical Data}

We reviewed hospital records of all patients presenting with ACS to obtain information on clinical demographics and medical history, including troponin negative unstable angina and troponin positive NSTEMI and acute STEMI with borderline lesions. Patients with ischemia driven heart failure were also included. Eight patients diagnosed as stable angina were included because after careful review their diagnosis appeared to be unstable angina. The respective clinical presentation data, major cardiac risk factors and cardiac biomarkers were collected.

\subsection{IVUS Analysis}

Segments of interest were selected around the most affected diseased segment harboring the minimal cross sectional area (CSA) or maximal plaque burden $(\mathrm{PB})$, as shown on Figure 1. Less diseased, most normal reference segments (distal and proximal-panels $\mathrm{A}$ and $\mathrm{E}$ on Figure 1) were also analysed. For the lesion runs that ended ostially like LAD-LM, LCx-LM, Diagonal-LAD or OM$\mathrm{LCx}$, the analysis was stopped at the bifurcation and taking into account the vessel size differences, only the distal reference segment was taken into account. The standard speed of the pullback runs were $0.5 \mathrm{~mm}$ per second. Each segment of interest was divided into $0.5 \mathrm{~mm}$ thin slices. Manually corrected digitally obtained intimal and external elastic membrane (EEM) tracings were carried out

Table 1. Inclusion and exclusion criteria.

\begin{tabular}{c} 
Inclusion criteria \\
\hline Patients presenting for ACS who underwent IVUS during diagnostic interventions \\
IVUS run carried out for borderline lesions evaluation (no tight stenosis). \\
IVUS run included segment of interest (lesion) and at least one reference vessel segment \\
IVUS run considered suitable for analysis with automatic pull back \\
Exclusion criteria \\
IVUS run carried out for the evaluation of a stent, acutely or previously implanted \\
IVUS run not including at least one of the two reference segments \\
IVUS run with manual pull back \\
IVUS run interrupted by side branches $>1.5$ mm in diameter \\
IVUS run considered inadequate technically
\end{tabular}




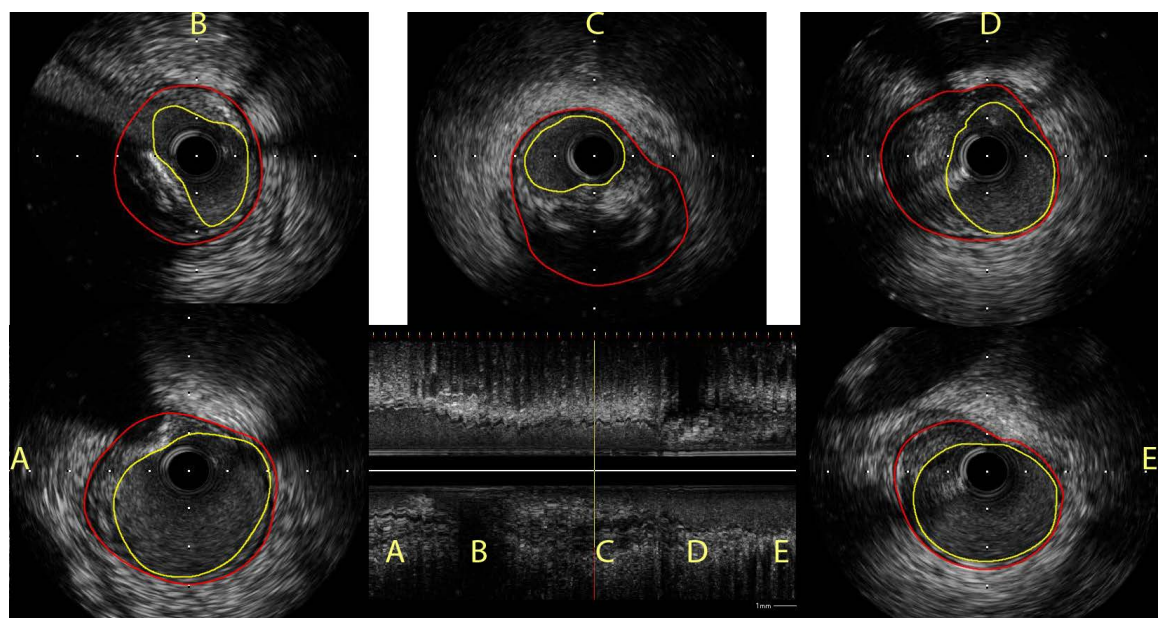

Figure 1. IVUS analysis of a mild LAD lesion. Measurements of luminal, plaque and vessel areas were done every $0.5 \mathrm{~mm}$, on the slices marked with the yellow ticks on the longitudinal view in the lower center panel. Panel A shows the proximal reference with an eccentric plaque between 6 and 9 o'clock. External elastic lamina is traced in red, lumen border in yellow. Lumen area was $11.0 \mathrm{~mm}^{2}$, vessel area $16.3 \mathrm{~mm}^{2}$ and plaque burden $32.5 \%$. The corresponding location on the longitudinal view is indicated by A. More distally, at the level of a small septal branch seen at 10 o'clock on panel B, a plaque with superficial calcium and shadowing behind is seen between 7 and 9 o'clock, with its corresponding location on the longitudinal view ( $B$, in the shadowed region). Panel $C$ shows the cross-section with the minimal lumen area $\left(3.7 \mathrm{~mm}^{2}\right)$, demonstrating positive remodeling (vessel area $14.8 \mathrm{~mm}^{2}$, plaque burden $75 \%$, remodeling index 1.1). Panel D shows distally where the plaque burden started to be $>50 \%$, accumulating between 7 and 11 o'clock (lumen area $6.7 \mathrm{~mm}^{2}$, vessel area $13.8 \mathrm{~mm}^{2}$, plaque burden 51\%). Panel E is the distal reference with the least plaque accumulation before any significant side branch (lumen area $8.7 \mathrm{~mm}^{2}$, vessel area $12.1 \mathrm{~mm}^{2}$, plaque burden $27.9 \%$ ).

using INDEC medical system software (EchoPlaque v 4.0, INDEC Medical System, Santa Clara, CA). The analysis was carried out in collaboration with the IVUS Core Laboratory of UMONS.

\subsection{IVUS Parameters}

- Cross Sectional Area (CSA, in $\left.\mathrm{mm}^{2}\right)$,

- IVUS slice thickness $(\mathrm{mm})=$ distance between 2 consecutively measured CSA,

- Average Lumen Diameter (ALD, mm),

- Lumen Area (LA, $\left.\mathrm{mm}^{2}\right)$,

- Average Vessel Diameter (AVD, mm),

- Vessel Area $\left(\mathrm{VA}, \mathrm{mm}^{2}\right)=$ EEM CSA,

- Plaque Area $\left(\mathrm{PA}, \mathrm{mm}^{2}\right)=\mathrm{VA}-\mathrm{LA}$,

- Plaque Burden $(\mathrm{PB}, \%)=100 \times(\mathrm{VA}-\mathrm{LA}) / \mathrm{VA}$,

- Remodeling Index $(\mathrm{RMI})=\frac{\mathrm{VA} \text { at CSA with minimal lumen area }}{\text { Average VA at distal and proximal references }}$,

- Lumen Volume $\left(\mathrm{LV}, \mathrm{mm}^{3}\right)=\sum$ Lumen CSA $\times$ IVUS slice thickness,

- Vessel Volume $\left(\mathrm{VV}, \mathrm{mm}^{3}\right)=\Sigma$ EEM CSA $\times$ IVUS slice thickness,

- Plaque Volume $=($ Vessel Volume - Lumen Volume $)$,

- Percent Volume Obstruction (\%) = $100 \times$ Plaque Volume/Vessel Volume. 


\subsection{Statistical Analysis}

The collected data were entered and analyzed using SPSS ver. 22. Descriptive statistics were done for all studied variable expressed as mean \pm standard deviation (SD) for continuous variables and as percentages for categorical variables. Bivariate analysis was done on categorical data, compared using chi-squared test. Analysis of variance (ANOVA) using Scheffee method and t-test were used appropriately to compare means of quantitative variables. Significant $\mathrm{P}$ value was set to be $<0.05$ through the study.

\section{Results}

A total of 181 patients were included, mean age was $57.8 \pm 10.1$ years. In 210 IVUS pullback, inclusion and exclusion criteria were met and $78 \%(\mathrm{n}=163)$ of these IVUS runs were recorded in men. Overall, $71 \%(\mathrm{n}=128)$ of our patients were diabetics with higher rate of associated cardiac risk factors as compared to non-diabetic group. STEMI was the most common clinical presentation $(47.8 \%$, $\mathrm{n}=88$ ). We observed that the patients in the diabetic group were more frequently suffering from a NSTEMI $(\mathrm{p}<0.01)$. Table 2 summarized the principal clinical features and sociodemographic data of our population according to the presence or absence of diabetes mellitus.

Among the 210 IVUS pullback analyzed, most of the segments of interest were located in the left anterior descending artery (155 IVUS runs, 73.8\%). Detailed locations of analyzed segments are summarized in Table 3.

As compared to non-diabetics, patients with DM had significantly larger plaque volume $\left(267.4 \pm 173.7 \mathrm{~mm}^{3}\right.$ versus $193.1 \pm 111.1 \mathrm{~mm}^{3}$ for non DM group, $\mathrm{p}<0.01)$, larger vessel volume $\left(495.9 \pm 313.6 \mathrm{~mm}^{3}\right.$ versus $358.2 \pm 181.7 \mathrm{~mm}^{3}$,

Table 2. Sociodemographic data and clinical features.

\begin{tabular}{|c|c|c|c|c|c|}
\hline & & $\begin{array}{c}\text { Total } \\
(\mathrm{n}=181)\end{array}$ & $\begin{array}{c}\text { DM } \\
(n=128)\end{array}$ & $\begin{array}{c}\text { NDM } \\
(n=53)\end{array}$ & $p$ value \\
\hline Age & & $58.2 \pm 10.0$ & $58.7 \pm 9.4$ & $56.8 \pm 11.3$ & 0.5 \\
\hline \multirow{2}{*}{ Gender } & Male & $139(77 \%)$ & $95(74 \%)$ & $44(83 \%)$ & \multirow{2}{*}{0.08} \\
\hline & Female & $42(23 \%)$ & $33(26 \%)$ & $9(17 \%)$ & \\
\hline \multirow{4}{*}{ Risk factors } & Hypertension & $136(75 \%)$ & $112(82 \%)$ & $24(18 \%)$ & $<0.01$ \\
\hline & Dyslipidemia & $103(60 \%)$ & 77 (75\%) & $26(25 \%)$ & 0.08 \\
\hline & Smoking & $90(50 \%)$ & $70(55 \%)$ & $20(38 \%)$ & \multirow{2}{*}{0.4} \\
\hline & Past smoking & $53(29 \%)$ & $35(27 \%)$ & $18(34 \%)$ & \\
\hline \multirow{6}{*}{$\begin{array}{c}\text { Clinical } \\
\text { presentation }\end{array}$} & STEMI & $88(47.8 \%)$ & $43(48.9 \%)$ & $45(51.1 \%)$ & 0.1 \\
\hline & NSTEMI & $35(19 \%)$ & $29(83 \%)$ & $6(17 \%)$ & $<0.01$ \\
\hline & $U A$ & $13(7.1 \%)$ & $11(58 \%)$ & $8(42 \%)$ & 0.5 \\
\hline & $S A P$ & $9(4.9 \%)$ & $8(89 \%)$ & $1(11 \%)$ & $<0.001$ \\
\hline & $I H F$ & $16(8.7 \%)$ & $16(100 \%)$ & $0(0 \%)$ & $<0.001$ \\
\hline & $S O B$ & $23(12.5 \%)$ & $21(91 \%)$ & $2(9 \%)$ & $<0.001$ \\
\hline
\end{tabular}

DM: diabetes mellitus group, NDM: non-diabetic group, STEMI: ST elevation myocardial infarction, NSTEMI: non ST elevation myocardial infarction, UA: unstable angina, SAP: stable angina pectoris, IHF: ischemic heart failure, SOB: shortness of breath (clinical presentations were not exclusive). ( $\mathrm{p}$ value for the comparison DM vs NDM). 
Table 3. Segments of interest in all IVUS studies.

\begin{tabular}{|c|c|c|c|}
\hline & & Number & Percentage \\
\hline \multirow{3}{*}{ LM } & Ostial LM & 2 & $1 \%$ \\
\hline & Mid LM & 34 & $16.2 \%$ \\
\hline & Distal LM & 15 & $7.1 \%$ \\
\hline \multirow{6}{*}{ LAD } & Ostial LAD & 8 & $3.8 \%$ \\
\hline & Proximal $L A D$ & 155 & $73.8 \%$ \\
\hline & $\operatorname{Mid} L A D$ & 111 & $52.9 \%$ \\
\hline & Distal LAD & 23 & $11 \%$ \\
\hline & $D 1$ & 32 & $15.2 \%$ \\
\hline & $D 2$ & 14 & $11 \%$ \\
\hline \multirow{5}{*}{ LCx } & Proximal LCX & 48 & $22.9 \%$ \\
\hline & Distal LCX & 7 & $3.3 \%$ \\
\hline & $O M 1$ & 35 & $16.7 \%$ \\
\hline & $O M 2$ & 20 & $9.5 \%$ \\
\hline & $P L$ & 6 & $2.9 \%$ \\
\hline \multirow{5}{*}{ RCA } & Ostial RCA & 1 & $0.5 \%$ \\
\hline & Proximal $R C A$ & 49 & $23.3 \%$ \\
\hline & Mid $R C A$ & 14 & $15.9 \%$ \\
\hline & Distal RCA & 34 & $16.2 \%$ \\
\hline & $P D A$ & 23 & $11 \%$ \\
\hline
\end{tabular}

LM: left main coronary artery, LAD: left anterior descending coronary artery, D: diagonal branch, LCx: left circumflex artery, OM: obtuse marginal artery, PL: posterolateral artery, RCA: right coronary artery, PDA: posterior descending artery. Although LM was included in the LAD (proximal and ostial) runs, LM runs were excluded from final IVUS analysis. Each IVUS run could include multiple segments $($ total $=631)$.

$\mathrm{p}<0.01)$, larger lumen volume $\left(231.2 \pm 156.2 \mathrm{~mm}^{3}\right.$ versus $163.5 \pm 87.9 \mathrm{~mm}^{3}, \mathrm{p}<$ $0.01)$ and longer lesions $(37.37 \pm 12.25 \mathrm{~mm}$ versus $29.93 \pm 8.43 \mathrm{~mm}, \mathrm{p}<0.01)$ as shown on Figure 2.

Both DM and NDM patients had an increased remodeling index without a significant difference (1.4 versus $1.3, \mathrm{p}=0.7$ ).

We did not observe any other significant difference between the two groups, in particular percent plaque volume and obstruction were not different (Table 4).

The above findings were more obvious in the STEMI subgroup. Diabetic patients with STEMI had significantly larger lumen diameter and area, bigger lumen, plaque and vessel volume and longer lesions as compared with non-diabetic patients with STEMI (Table 5). In patients with NSTEMI, UA or equivalents, we did not find a statistically significant difference between DM and NDM groups.

\section{Discussion}

Diabetes mellitus has been associated with an increased risk of cardiovascular 

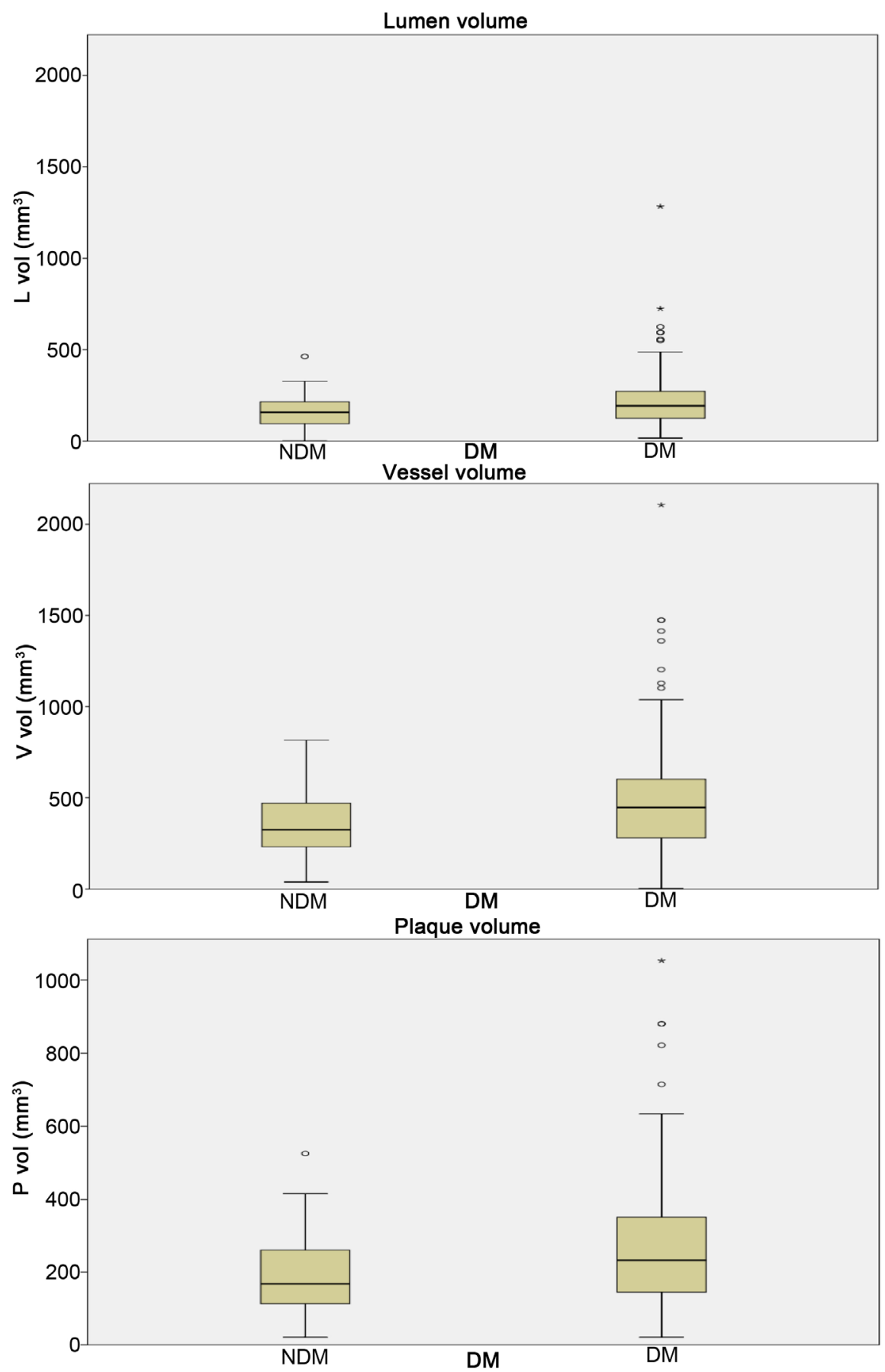

Figure 2. Box plot with scatter diagram for Lumen volume ( $\mathrm{L}$ vol), Vessel volume (V vol) and Plaque volume ( $\mathrm{P}$ vol), in $\mathrm{mm}^{3}$, for DM vs NDM patients.

disease. Moreover, individuals with diabetes are generally more difficult to treat due to associated comorbidities, more complex coronary lesions and more frequent in-stent restenosis. The aim of the current study was to establish an intravascular profile of coronary stenosis in Saudi diabetic patients.

It is well known, based on previous angiographic or post mortem studies, that diabetic patients experience more extensive atherosclerosis with more frequent multivessel disease and more severe and diffuse coronary lesions [6] [7] [8] [9]. 
Table 4. IVUS finding in lesion segment in diabetics patients as compared to non-diabetics.

\begin{tabular}{|c|c|c|c|}
\hline & $\mathrm{DM}$ & NDM & $\mathrm{p}$ value \\
\hline ALD (mm) & $2.7 \pm 0.5$ & $2.6 \pm 0.5$ & 0.2 \\
\hline $\operatorname{AVD}(\mathrm{mm})$ & $3.9 \pm 0.7$ & $3.8 \pm 0.7$ & 0.2 \\
\hline $\mathrm{LA}\left(\mathrm{mm}^{2}\right)$ & $5.9 \pm 2.4$ & $5.5 \pm 2.2$ & 0.2 \\
\hline VA $\left(\mathrm{mm}^{2}\right)$ & $12.5 \pm 4.4$ & $11.7 \pm 4.4$ & 0.3 \\
\hline $\mathrm{PA}\left(\mathrm{mm}^{2}\right)$ & $6.6 \pm 2.5$ & $6.3 \pm 2.8$ & 0.4 \\
\hline PB (\%) & $53 \pm 10$ & $53 \pm 10$ & 0.9 \\
\hline $\operatorname{MVD}(\mathrm{mm})$ & $3.7 \pm 0.6$ & $3.6 \pm 0.6$ & 0.2 \\
\hline $\operatorname{MLD}(\mathrm{mm})$ & $3.3 \pm 1.5$ & $3.1 \pm 1.3$ & 0.1 \\
\hline $\mathrm{LL}(\mathrm{mm})$ & $37.4 \pm 12.3$ & $29.9 \pm 8.4$ & $<0.01$ \\
\hline $\mathrm{V} \operatorname{vol}\left(\mathrm{mm}^{3}\right)$ & $495.9 \pm 313.6$ & $358.2 \pm 181.7$ & $<0.01$ \\
\hline L vol $\left(\mathrm{mm}^{3}\right)$ & $231.2 \pm 156.2$ & $163.5 \pm 87.9$ & $<0.01$ \\
\hline$P \operatorname{vol}\left(\mathrm{mm}^{3}\right)$ & $267.4 \pm 173.7$ & $193.1 \pm 111.1$ & $<0.01$ \\
\hline PPV (\%) & $52.9 \pm 8.9$ & $52.7 \pm 10.9$ & 0.8 \\
\hline PVO (\%) & $47.2 \pm 8.9$ & $47.2 \pm 10.8$ & 0.9 \\
\hline RMI & $1.4 \pm 0.5$ & $1.3 \pm 0.5$ & 0.7 \\
\hline
\end{tabular}

DM: diabetes mellitus group, NDM: non-diabetic group, ALD: average lumen diameter, AVD: average vessel diameter, LA: luminal area, VA: vessel area, PA: plaque area, PB: plaque burden, MVD: minimal vessel diameter, MLD: minimal luminal diameter, LL: lesion length, $\mathrm{V}$ vol: vessel volume, $\mathrm{L}$ vol: luminal volume, $\mathrm{P}$ vol: plaque volume, PPV: percent plaque volume, PVO: percent volume obstruction, RMI: remodeling index.

Table 5. Major IVUS finding according to clinical presentation in diabetic patients compared to non-diabetics.

\begin{tabular}{|c|c|c|c|c|c|c|c|c|c|}
\hline & \multicolumn{2}{|c|}{ STEMI } & \multirow{2}{*}{$\mathrm{p}$} & \multicolumn{2}{|c|}{ NSTEMI } & \multirow{2}{*}{$\mathrm{p}$} & \multicolumn{2}{|c|}{ UA or equivalent } & \multirow{2}{*}{$\mathrm{p}$} \\
\hline & $D M$ & $N D M$ & & $D M$ & $N D M$ & & $D M$ & $N D M$ & \\
\hline $\operatorname{ALD}(\mathrm{mm})$ & $2.8 \pm 0.6$ & $2.5 \pm 0.5$ & 0.02 & $2.6 \pm 0.5$ & $2.8 \pm 0.7$ & 0.5 & $2.7 \pm 0.6$ & $2.7 \pm 0.5$ & 0.8 \\
\hline $\mathrm{LA}\left(\mathrm{mm}^{2}\right)$ & $6.4 \pm 2.6$ & $5.2 \pm 1.9$ & 0.02 & $5.6 \pm 2.0$ & $6.6 \pm 3.9$ & 0.6 & $6.0 \pm 2.7$ & $6.2 \pm 2.5$ & 0.8 \\
\hline $\mathrm{LL}(\mathrm{mm})$ & $42.7 \pm 13.9$ & $29.0 \pm 8.1$ & $<0.01$ & $33.1 \pm 10.2$ & $25.1 \pm 4.2$ & 0.2 & $34.8 \pm 10.9$ & $33.6 \pm 11.9$ & 0.8 \\
\hline $\mathrm{V} \operatorname{vol}\left(\mathrm{mm}^{3}\right)$ & $571.2 \pm 350.8$ & $336 \pm 172.6$ & $<0.01$ & $412.6 \pm 230.5$ & $356.4 \pm 153.8$ & 0.5 & $480.5 \pm 333.3$ & $413.6 \pm 231.9$ & 0.4 \\
\hline $\mathrm{L} \operatorname{vol}\left(\mathrm{mm}^{3}\right)$ & $273.6 \pm 168.0$ & $150.0 \pm 77.4$ & $<0.01$ & $194.1 \pm 92.3$ & $160,5 \pm 68.3$ & 0.3 & $226.9 \pm 184.4$ & $201.6 \pm 126.8$ & 0.6 \\
\hline $\mathrm{P} \operatorname{vol}\left(\mathrm{mm}^{3}\right)$ & $297.6 \pm 194.9$ & $183.9 \pm 110.6$ & $<0.01$ & $232.2 \pm 136.6$ & $195.9 \pm 96.0$ & 0.4 & $253.6 \pm 176.4$ & $212.0 \pm 132.7$ & 0.4 \\
\hline RMI & $1.41 \pm 0.46$ & $1.29 \pm 0.62$ & 0.3 & $1.20 \pm 0.40$ & $0.98 \pm 0.2$ & 0.2 & $1.34 \pm 0.6$ & $1.57 \pm 0.57$ & 0.5 \\
\hline
\end{tabular}

STEMI: ST elevation myocardial infarction, NSTEMI: non ST elevation myocardial infarction, UA: unstable angina, DM: diabetes mellitus group, NDM: non-diabetic group, ALD: average lumen diameter, LA: luminal area, LL: lesion length, V vol: vessel volume, L vol: luminal volume, P vol: plaque volume, RMI: remodeling index.

However, other researches demonstrated that the angiographic profiles are similar among diabetic and non-diabetic patients [10] [11]

Our study demonstrates that in Saudi diabetic patients with acute coronary syndrome, coronary lesions are longer, with more plaque but without an increased remodelling index as compared to non-diabetics.

While recent IVUS studies focused on plaque virtual histology in the diabetic population, few trials compared quantitative intravascular parameters and showed 
controversial results. Hong et al. [12] reported similar results to ours showing that DM patients with ACS seems to have relatively larger vessel, lumen and plaque volume than NDM patients (respectively in $\mathrm{mm}^{3} 272 \pm 211$ vs $263 \pm 220$, $131 \pm 103$ vs $129 \pm 100$ and $141 \pm 115$ vs $134 \pm 126$; p: NA). Larger plaque volume was also reported in a sub analysis of the TRUTH Study [13] but unlike our study DM patients had relatively smaller lumen volume and shorter lesions. In 86 patients with ACS, there was no significant differences found in culprit lesions quantitative analysis among the two groups [15]. These studies were conducted in eastern Asiatic population with different baseline characteristics and inclusion criteria.

In a recent prospective observational study, Kuroda et al did not find a significant difference between DM and NDM patients in terms of plaque volume, plaque burden and lesion length [14]. However, ACS were excluded from this study.

Our patients, DM and NDM ones, had an increased remodeling index. This finding goes against previous studies that have shown a high prevalence of negative artery remodeling in diabetics patients [16] [17] [18].

Conducted in different populations, these controversial results should be taken with caution.

\section{Study Limitations}

The current study was retrospective and monocentric. Detailed biological features are not reported, considered out of the scope of this report. No qualitative analysis of the plaques was attempted, knowing the variability of grey-scale interpretation in this population [19].

\section{Conclusion}

Diabetic patients with acute coronary syndrome in Saudi Arabia have larger vessel, lumen and plaque volume and longer lesions. This is the first intravascular database in the region that could lead to a better understanding of coronary artery disease particularities in our patients, a better therapeutic management and more favorable prognosis.

\section{Acknowledgements}

This work would not have been completed without the help of Mr Nadir Siddiqi with his expert contribution in data analysis. We also would like to thank the cardiovascular technologists Lamis Al Shahrani, Amal Al Bunyan, Shiraz Mirza and Ola $\mathrm{Al}$ Kathiri who dedicated their time and effort to collecting and analysing the IVUS runs and collecting the patients' clinical database.

\section{References}

[1] Berry, C., Tardif, J.C. and Bourassa, M.G. (2007) Coronary Heart Disease in Patients with Diabetes. Journal of the American College of Cardiology, 49, 643-656. https://doi.org/10.1016/j.jacc.2006.09.045 
[2] Danaei, G., Finucane, M.M., Lu, Y., Singh, G.M., Cowan, M.J., Paciorek, C.J., Lin, J.K., Farzadfar, F., Khang, Y., Stevens, G.A., Rao, M., Ali, M.K., Riley, L.M., Robinson, C.A. and Ezzati, M. (2011) National, Regional, and Global Trends in Fasting Plasma Glucose and Diabetes Prevalence Since 1980: Systematic Analysis of Health Examination Surveys and Epidemiological Studies with 370 Country-Years and 2.7 Million Participants. The Lancet, 378, 31-40. https://doi.org/10.1016/s0140-6736(11)60679-x

[3] Al-Nozha, M.M., Al-Maatouq, M.A., Al-Mazrou, Y.Y., Al-Harthi, S.S., Arafah, M.R., Khalil, M.Z., Khan, N.B., Al-Khadra, A., Al-Marzouki, K., Nouh, M.S., Abdullah, M., Attas, O., Al-Shahid, M.S. and Al-Mobeireek, A. (2004) Diabetes Mellitus in Saudi Arabia. Saudi Medical Journal, 25, 1603-1610.

[4] Al-Nozha, M.M., Arafah, M.R., Al-Mazrou, Y.Y., Al-Maatouq, M.A., Khan, N.B., Khalil, M.Z., Al-Khadra, A.H., Al-Marzouki, K., Abdullah, M.A., Al-Harthi, S.S., Al-Shahid, M.S., Nouh, M.S. and Al-Mobeireek, A. (2004) Coronary Artery Disease in Saudi Arabia. Saudi Medical Journal, 25, 1165-1171.

[5] Singh, M., Arora, R., Kodumuri, V., Khosla, S. and Jawad, E. (2011) Coronary Revascularization in Diabetic Patients: Current State of Evidence. Experimental \& Clinical Cardiology, 16, 16-22.

[6] Dortimer, A.C., Shenoy, P.N., Shiroff, R.A., Leaman, D.M., Babb, J.D., Liedtke, A.J. and Zelis, R. (1978) Diffuse Coronary Artery Disease in Diabetic Patients: Fact or Fiction? Circulation, 57, 133-136. https://doi.org/10.1161/01.CIR.57.1.133

[7] Waller, B.F., Palumbo, P.J., Lie, J.T. and Roberts, W.C. (1980) Status of the Coronary Arteries at Necropsy in Diabetes Mellitus with Onset after Age 30 Years. Analysis of 229 Diabetic Patients with and without Clinical Evidence of Coronary Heart Disease and Comparison to 183 Control Subjects. The American Journal of Medicine, 69, 498-506.

[8] Vigorito, C., Betocchi, S., Bonzani, G., Giudice, P., Miceli, D., Piscione, F. and Condorelli, M. (1980) Severity of Coronary Artery Disease in Patients with Diabetes Mellitus. Angiographic Study of 34 Diabetic and 120 Nondiabetic Patients. American Heart Journal, 100, 782-787. https://doi.org/10.1016/0002-8703(80)90056-3

[9] Zornitzki, T., Ayzenberg, O., Gandelman, G., Vered, S., Yaskil, E., Faraggi, D., Caspi, A., Goland, S., Shvez, O., Schattner, A. and Knobler H. (2007) Diabetes, but Not the Metabolic Syndrome, Predicts the Severity and Extent of Coronary Artery Disease in Women. QJM-Monthly Journal of the Association of Physicians, 100, 575-581. https://doi.org/10.1093/qjmed/hcm066

[10] Hochman, J.S., Phillips, W.J., Ruggieri, D. and Ryan, S.F. (1988) The Distribution of Atherosclerotic Lesions in the Coronary Arterial Tree: Relation to Cardiac Risk Factors. American Heart Journal, 116, 1217-1222. https://doi.org/10.1016/0002-8703(88)90443-7

[11] Pajunen, P., Nieminen, M.S., Taskinen, M.R. and Syvänne, M. (1997) Quantitative Comparison of Angiographic Characteristics of Coronary Artery Disease in Patients with Noninsulin-Dependent Diabetes Mellitus Compared with Matched Nondiabetic Control Subjects. American Journal of Cardiology, 80, 550-556.

[12] Hong, Y.J., Jeong, M.H., Choi, Y.H., Song, J.A., Ahmed, K., Kim, D.H., Lee, K.H., Lee, M.G., Park, K.H., Sim, D.S., Yoon, N.S., Yoon, H.J., Kim, K.H., Park, H.W., Kim, J.H., Ahn, Y., Cho, J.G., Park, J.C. and Kang, J.C. (2011) Relationship between Microalbuminuria and Vulnerable Plaque Components in Patients with Acute Coronary Syndrome and with Diabetes Mellitus. Virtual Histology-Intravascular Ultrasound. Circulation Journal, 75, 2893-2901.

https://doi.org/10.1253/circj.cj-11-0663 
[13] Nozue, T., Yamamoto, S., Tohyama, S., Fukui, K., Umezawa, S., Onishi, Y., Kunishima, T., Sato, A., Nozato, T., Miyake, S., Takeyama, Y., Morino, Y., Yamauchi, T., Muramatsu, T., Hibi, K., Terashima, M. and Michishita, I. (2012) Impact of Diabetes Mellitus on Coronary Atherosclerosis and Plaque Composition under Statin Therapy-Subanalysis of the TRUTH Study. Circulation Journal, 76, 2188-2196. https://doi.org/10.1253/circj.CJ-11-1303

[14] Kuroda, M., Shinke, T., Sakaguchi, K., Otake, H., Takaya, T., Hirota, Y., Sugiyama, D., Nakagawa, M., Hariki, H., Inoue, T., Osue, T., Taniguchi, Y., Iwasaki, M., Nishio, R., Kinutani, H., Konishi, A., Hiranuma, N., Takahashi, H., Terashita, D. and Hirata K. (2015) Effect of Daily Glucose Fluctuation on Coronary Plaque Vulnerability in Patients Pre-Treated with Lipid-Lowering Therapy: A Prospective Observational Study. JACC: Cardiovascular Interventions, 8, 800-811.

https://doi.org/10.1016/j.jcin.2014.11.025

[15] Takaoka, N., Tsujita, K., Kaikita, K., Hokimoto, S., Yamanaga, K., Komura, N., Chitose, T., Ono, T., Mizobe, M., Horio, E., Sato, K., Nakayama, N., Saito, M., Iwashita, S., Kojima, S., Tayama, S., Sugiyama, S., Nakamura, S. and Ogawa, H. (2014) Intravascular Ultrasound Morphology of Culprit Lesions and Clinical Demographics in Patients with Acute Coronary Syndrome in Relation to LowDensity Lipoprotein Cholesterol Levels at Onset. Heart and Vessels, 29, 584-595. https://doi.org/10.1007/s00380-013-0401-7

[16] Abizaid, A.S., Mehran, R., Mintz, G.S., Abizaid, A.A., Dangas, G., Lansky, A.J., Farkouh, M., Adamian, M.G., Aymong, E.D., Negoita, M., Hjazi, I., Costantini, C., Kobayashi, Y., Moses, J.W., Stone, G.W. and Leon, M.B.(2003) Impact of Diabetes on Coronary Remodeling in Patients with Acute Coronary Syndromes: An Intravascular Ultrasound Study. Journal of the American College of Cardiology, 41, 8-9.

[17] Weissman, N.J., Sheris, S.J., Chari, R., Mendelsohn, F.O., Anderson, W.D., Breall, J.A., Tanguay, J.F. and Diver, D.J. (1999) Intravascular Ultrasonic Analysis of Plaque Characteristics Associated with Coronary Artery Remodeling. American Journal of Cardiology, 84, 37-40. https://doi.org/10.1016/S0002-9149(99)00188-5

[18] Jensen, L.O., Thayssen, P., Mintz, G.S., Egede, R., Maeng, M., Junker, A., Galloee, A., Christiansen, E.H., Pedersen, K.E., Hansen, H.S. and Hansen, K.N. (2008) Comparison of Intravascular Ultrasound and Angiographic Assessment of Coronary Reference Segment Size in Patients with Type 2 Diabetes Mellitus. American Journal of Cardiology, 101, 590-595. https://doi.org/10.1016/j.amjcard.2007.10.020

[19] Katouzian, A., Sathyanarayana, S., Baseri, B., Konofagou, E.E. and Carlier, S.G. (2008) Challenges in Atherosclerotic Plaque Characterization with Intravascular Ultrasound (IVUS): From Data Collection to Classification. IEEE Transactions on Information Technology in Biomedicine, 12, 315-327. https://doi.org/10.1109/TITB.2007.912352 
Submit or recommend next manuscript to SCIRP and we will provide best service for you:

Accepting pre-submission inquiries through Email, Facebook, LinkedIn, Twitter, etc. A wide selection of journals (inclusive of 9 subjects, more than 200 journals)

Providing 24-hour high-quality service

User-friendly online submission system

Fair and swift peer-review system

Efficient typesetting and proofreading procedure

Display of the result of downloads and visits, as well as the number of cited articles Maximum dissemination of your research work

Submit your manuscript at: http://papersubmission.scirp.org/

Or contact wicd@scirp.org 